his isinglass plaster that he has no greater number of cases of prolapse, but in his last report there are thirty-three per cent. of iridectomies. The iris which is cut away, cannot prolapse. The number of intercurrent iridectomies in the simple operation must come into consideration.

Dr.J.J. Chisolm, Baltimore:-The report to which Dr. $\mathrm{Knapp}$ refers is a hospital report in which are included cases done by my assistants and they do iridectomies. The bospital report does not refer to my individual cases.

Dr. H. Knapp, of New York:-The danger in the simple operation comes from the prolapse of the iris, as it does in the combined operation and the danger from prolapse in the combined operation (the angular incarcerations) according to my experience is greater than the prolapse in the simple operation. Since I abandoned iridectomy, I have seen much less iritis, irido-cyclitis and other complications than before. Simple extraction is, I think, the safest operation and that is its principal claim. When I examine eyes on which extraction with iridectomy has been done by myself or others, I find incarceration of the iris in the corners not so rarely and incarceration of the capsule in the majority of cases. This leads to many reactive processes including sympathetic ophthalmia.

I never cut a prolapse, whether spontaneous or traumatic, unless I get it fresh. If there is blenorrhoea or another infective process, it is criminal to cut a prolapse, as this opens a door for the entrance of germs into the interior. These are only the immediate results of cutting the iris, but the later ones are just as deleterious. In the series of one thousand combined operations which $I$ have reported, there were two or three cases of late suppuration following incarcerated iris. In some cases the incarceration was so small that it could not be seen. As a result of exposure there was purulent iritis and ophthalmitis in eyes that had been quiet for years. Such cases are well known. The danger from immediate prolapse of the iris is greater when the iris is cut than when it is left untouched. Some years ago while engaged in experiments with infective germs, I injected pyogenic cocci into the anterior chamber of rabbits. On examination of these eyes I found the cornea was full of germs, but the iris almost free from them. The iris protects the deeper parts. This fact may serve as a rule for guidance, that we should make an iridectomy only when the eye is still aseptic. Otherwise it is better to postpone the operation until all inflammatory irritation past.

The occurrence of prolapse is chiefly due to two things. The one is traumatism. In fifty per cent. of the cases there is a direct history of hurt or blood in the anterior chamber to indicate that the part had been injured. The second cause is a peripheric section. The introduction of excision of the iris was not the result of scientific thinking. Iridectomy was made because its originators could not help it. A large peripheric incision without iridectomy is impossible. This is not so when the section is placed in the limbus. As we cannot always be accurate, let us rather encroach upon the cornea than on the sclerotic. On the whole the subject is certainly one that still requires careful study and prolonged experience.

\section{DOUBLE CONGENITAL DISLOCATION OF THE LENS.}

Read in the Section of Ophthalmology, at the Forty-third Annual Meet ing of the American Medical Association, held at Detroit, Mich.,

BY GEORGE FRIEBIS, M.D.,

of PHILADELPHIA.

On Jan. 3, of this year, the Rev. Dr. B. of Philadelphia, brought his son Walter, now 7 years of age, to me desiring that something be done to improve his sight; stating that for some time past both he and the teacher had noticed that the boy had great difficulty in clearly defining objects, which were easily distinguished by other pupils of his class, at a reasonable distance from him, nor could he well define small letters at the usual reading distance. The examination revealed the rare condition known as congenital dislocation of the lenses; and in this instance the dislocation was symmetrical. I have the honor to show you an excellent drawing, made by Dr. J. Madison Taylor, of Philadelphia, illustrating the conditions. The lens in each eye was tilted upward, slightly backward and inward. The iris was responsive to light stimulation and only on close scrutiny could a slight tremulousness of the same, in the inferior, outer quadrant be detected. The fundus viewed by both the direct and indirect methods showed the curious phenomenon of aphakia with myopic refraction in both eyes. The lower periphery of the upward dislocated lens appeared as an irregularly marked black line. The fibres of the zone of $\mathrm{Zinn}$, described by some observers upon the subject, as clearly discernible in the aphakial interspace, were absent in this case. Owing to the child's unsteadiness it was impossible to measure with accuracy the degree of refraction either of the lens or aphakial portion of the eye. I confess to have been slightly puzzled by the appearance of the lens, viewed by oblique illumination, deeming it at first glance, because of the strong grayish reflex of the lens, though entirely transparent by other methods of examination, a form of congenital cataract. The vitreous body and fundus were normal; the tension likewise. The test for vision in the $R$. E. $=15-$ 70 , I. E. $15-50$ imperfectly ; a manifest refraction at this time, which was rather hurriedly performed, gave a negative result. Upon a subsequent occasion, the pupils being dilated by atropine, I thoroughly tested his vision with different combinations, sphericals, cylinders and sphero-cylinders - and - which would be too wearisome to enumerate ; I found the following formula gave the best results. R. E. S. $-1=\mathrm{cyl} .-1$ ax. $180=15-70$ clearly, but in a moment he would again lose certain letters in the line. L. E. S. $-1=$ 15-50 perfectly but as in the $R$. E. he could not hold the line satisfactorily. A few weeks later on, I again tested his refraction without mydriatic or glasses. At this time vision for distance in the R. E. $=15-70$, L. E. $15-50$ imperfectly, these tests proving conclusively that the child was also amblyopic; a usual concomitant of congenital dislocation. Vision for reading was not improved by glasses in the slightest degree. In fact vision for small letters at about 8 inches was slightly better without glasses and he defined letters Snellen 1 at 8 to 10 inches fairly well, but had to search for them, this showing an amplitude of about 2 inches in each eye and that accommodation was not entirely abolished. Glasses were not prescribed. The field was tested and found to be normal ; the color sense was unimpaired. Diplopia usually present and demonstrable in many cases of this character could not on account of the youth of the patient and some mental obtuseness be established.

In passing I would state, that Dr. Chas. S. Turnbull also saw this little patient with me but by no method of examination could we detect any other structural changes than those already mentioned. Both parents are healthy and have a family of nine children, all of whom have excellent vision. As some observers hold that congenital dislocation is largely due to heredity and that consanguinity often plays an important part in its causation, I closely questioned the father, a very intelligent man, as to his family history. I could not obtain a satisfactory answer confirmatory of his theory, but he stated that he had no definite knowledge of any hereditary tendencies in his wife's family. The late Dr. Wm. S. Little of Philadelphia, reported at the $19 \mathrm{th}$ meeting of the A. O. Society two cases of congenital dislocations of the lens, one was non-symmetrical and the other symmetrical. The latter case occurring in the practice of Dr. Turnbull, by whose courtesy I am enabled to show you an additional cut representing a double inward dislocation. Although this cut was shown at the meeting of the American Ophthaimological Society in 1883 , yet I deemed it of sufficient interest, by way of contrast with my own case, to bring it to the attention of this meeting. Both patients were likewise markedly amblyopic and in each instance refraction of the existing ametropia gave a useful degree of vision. In Dr. Turnbull's case the lenses were so far dislocated as to nuake the eyes almost aphakial, but by the use of cataract glasses useful vision was obtained. Dr. Turnbull's patient gave no history of malformations in any of the members of his family or near. relatives, but had himself a highly vaulted roof of mouth. Dr. Little's patient said that he had a cousin similarly affected and that 
his father was color blind. These are the only two cases that $I$ have been able to find in the more recent literature within the past decade, clearly recorded as congenital dislocations, although foreign literature teems with a goodly number of this congenital aberration. Dr. Doensch in an admirable monograph enters at some length into the history of the subject, in which it appears, that earlier writers made no marked distinction between congenital and spontaneous dislocations, both being looked upon by the majority of observers as indicative of a morbid process. Not until Sippell's excellent essay upon the subject, who was himself afflicted with congenital dislocation, was a distinction made and the diagnosis accepted, that one was a morbid condition in which the lens was liable to further degeneration, such as sinking of the lens and loss of transparency, etc., while congenital dislocation is a permanent condition not likely to undergo such changes, and in which heredity and consanguinity are the most probable etiological factors. In support of the theory of heredity, Sippell quotes a number of cases, three of von Graefe's and three of his own, in which the condition was found to exist in one instance and in the others traceable to father and daughter. Graefe, Sippell, Dixon and other authors give strong support, in my opinion, to the heredity theory; a number of cases are reported of brothers and sisters of the same family, who were so effected. In Jonathan Wild's interesting little book on "Congenital Malformations of the Eye," which was kindly brought to my attention by Dr. Oliver, a member of this Society, I found four cases, which he quotes from Dixon, all occurring in the same family, and though the history of the case presented by me does not sustain the theory of heredity, it is but an isolated case and an exception to the rule, and my conclusions based upon a brief study of the literature of the subject, I would formulate as follows:

First, that congenital ectopia lentis is usually double.

Second, that it is a congenital malformation, the cause of which is not yet positively established.

Third, that amblyopia and ametropia are always concomitant conditions and that the majority of cases, so far reported, sustain the theory of heredity as the primary cause.

\section{Discussion.}

Dr. D. C. Bryant, Omaha:-I have under my care a family of seven persons, five of whom had the same trouble, dislocation of the lens. The parents have healthy eyes. In another family the mother and three children suffer with the same trouble. There is no myopia in these cases.

Dr. B. Alexander Randall, Philadelphia:-I remember seeing two cases of this condition it Jeager's clinic on the same day. In one the dislocation was up and in the other up and to the left. The point was made by Jeager that he regarded the symmetrical displacement as congenital, and the other as probably of traumatic origin; and I would ask if those of wide experience can throw light upon this question, which my own observation would leave an open one.

Dr. Edward P. Morrow:-It has been my fortune to see four cases of dislocation of the lens and to receive the history of another in the same family. The drawing shown is a perfect picture of the first case seen, a boy about 12 years of age having a double dislocation upwards and inwards. Shortly following this his sister presented herself, showing precisely the same condition, again inside of the year another sister and the mother similarly affected. From the mother, a history was obtained of her sister, whom she said was affected in a like manner. Each of these cases would accept either a convex or a concave lens with slight improvement of vision. There was no movement of the lenses obtained in any of the cases.
Dr. Eugene Smith, Detroit:-It may be of interest to speak of a case of voluntary dislocation of the lenses that has come under my observation. When the individual tipped his head forward both lenses would come through the pupils, when he threw his head back the lenses would return. I advised iridodesis and in the meantime used eserine. He went to New York where operation was advised against and pilocarpine prescribed.

Dr. George Friebis, Philadelphia :-The remarks which have been made are corroborative and sustain the views I have expressed, that heredity is the most prominent etiological element in the production of this condition.

\section{INFANTILE CATARACT.}

Read in the Section of Ophthalmology, at the Forty-third Annual Meeting of the American Medical Association, held at Detroit, Mich..
June, 1892.

BY AI.BERT R. BAKER, M.D., OF CLEVEIAND, $O$.

PROFESSOR OF DISEASES OF THE FYE, EAR AND THROAT, IN THE MEDICAL DEPARTMEXT OF WOOSTER UNIVERSITY; OCULIST A YD AURIST TO THE CITY, WOMEN AND CHILDREN'S AND UNIVERSITY HOSPITALS.

I selected this subject, not because I had any new facts to communicate or new operations to propose, or new theories to advance; but because my experience, observation and reading has led me to believe that, as a rule, we do not treat infantile cataract as successfully and as intelligently as we do many other eye diseases. If I am correct in this supposition, an interchange of ideas on this important subject at this time cannot fail to be of value.

I know of no subject more perplexing to the medical student than the classification of cataracts; they have been classified as to age as congenital, infantile, juvenile and senile, as to consistency as fluid, soft, mixed and hard. They may be capsular or lenticular. Capsular cataracts may be pyramidal anterior polar, posterior polars, or degenerative. Lenticular cataracts may be nuclear, cortical or zonular. Cataracts have been classified as to cause, as albuminuric, diabetic, traumatic, etc. They may be simple or complicated, primary or secondary, ripe or unripe, mature, immature or hypermature. This list might be continued almost indefinitely, but is sufficient to illustrate the protean forms in which lenticular opacity presents itself to the ophthalmic surgeon, and it is in the child that we find the most remarkable variation, in the cases brought to our notice. It was that prince of British ophthalmologists, Mr. George Critchett, in a lecture published in the London Lancet as long ago as 1855, who said that "Congenital cataract deserves very careful notice on account of the numerous aspects it assumes, the frequency with which it is overlooked, the baneful influence it may exert upon the prospects and career of the patients, and the favorable results of suitable treatment. The more we have an opportunity of observing these cases, the more evident does it become that nature revels in variety. Even in her morbid operations, when we fancy we have exhausted every possible form, sume new manifestation presents itself."

For our present purpose it is not necessary to enter into an extended discussion of that much debated question, whether cataract is ever congenital, as it makes little practical difference (although the question may have an etiological value), whether it is present at birth or comes a few hours or days afterward. Dr. Alt ${ }^{1}$ saw a case of total lenticular cataract in a baby 24 hours old. The writer saw a milky white

1 American Journal of Ophthalmology, December, 1887. 